\title{
Tenacibaculum finnmarkense sp. nov., a fish pathogenic bacterium of the family Flavobacteriaceae isolated from Atlantic salmon
}

\author{
Sverre Bang Småge • Øyvind Jakobsen Brevik $\cdot$ Henrik Duesund • \\ Karl Fredrik Ottem $\cdot$ Kuninori Watanabe $\cdot$ Are Nylund
}

Received: 24 August 2015/Accepted: 1 December 2015/Published online: 11 December 2015

(C) The Author(s) 2015. This article is published with open access at Springerlink.com

\begin{abstract}
A novel Gram-stain negative, aerobic, nonflagellated, rod-shaped gliding bacterial strain, designated $\mathrm{HFJ}^{\mathrm{T}}$, was isolated from a skin lesion of a diseased Atlantic salmon (Salmo salar L.) in Finnmark, Norway. Colonies were observed to be yellow pigmented with entire and/or undulating margins and did not adhere to the agar. The 16S rRNA gene sequence showed that the strain belongs to the genus Tenacibaculum (family Flavobacteriaceae, phylum 'Bacteroidetes'). Strain $\mathrm{HFJ}^{\mathrm{T}}$ exhibits high 16S rRNA gene sequence similarity values to Tenacibaculum dicentrarchi NCIMB $14598^{\mathrm{T}}$ $(97.2 \%)$. The strain was found to grow at $2-20{ }^{\circ} \mathrm{C}$ and only in the presence of sea salts. The respiratory quinone was identified as menaquinone 6 and the major fatty acids were identified as summed feature 3 (comprising $\mathrm{C}_{16: 1}$ $\omega 7 \mathrm{c}$ and/or iso- $\mathrm{C}_{15: 0} 2-\mathrm{OH}$ ), iso- $\mathrm{C}_{15: 0}$, anteiso- $\mathrm{C}_{15: 0 \text {, }}$, iso$\mathrm{C}_{15: 1}$ and iso- $\mathrm{C}_{15: 0} 3-\mathrm{OH}$. The DNA $\mathrm{G}+\mathrm{C}$ content was determined to be $34.1 \mathrm{~mol} \%$. DNA-DNA hybridization and comparative phenotypic and genetic tests were
\end{abstract}

S. B. Småge $(\bowtie) \cdot K$. Watanabe $\cdot$ A. Nylund Fish Disease Research Group, Department of Biology, University of Bergen, Thormøhlensgt 55, Bergen 5020, Norway

e-mail: sverre.smage@cermaq.com

S. B. Småge · Ø. J. Brevik · H. Duesund

Cermaq Group AS, Dronning Eufemias Gate 16, Oslo 0191, Norway

K. F. Ottem

Cermaq Norway, Gjerbakknes, Nordfold 8286, Norway performed with the phylogenetically closely related type strains, T. dicentrarchi NCIMB $14598^{\mathrm{T}}$ and Tenacibaculum ovolyticum NCIMB $13127^{\mathrm{T}}$. These data, as well as phylogenetic analyses, suggest that strain $\mathrm{HFJ}^{\mathrm{T}}$ should be classified as a representative of a novel species in the genus Tenacibaculum, for which the name Tenacibaculum finnmarkense sp. nov. is proposed; the type strain is $\mathrm{HFJ}^{\mathrm{T}}=\left(\mathrm{DSM} 28541^{\mathrm{T}}=\operatorname{NCIMB} 42386^{\mathrm{T}}\right)$.

Keywords Norway Polyphasic taxonomy · Salmon farming · Skin lesions · Ulcerative disease $\cdot$ Winter ulcers

\section{Introduction}

During an outbreak of an ulcerative disease in Atlantic salmon at a seawater site in Finnmark, Norway, long rod shaped bacteria were found to predominate in the skin lesions. One strain of these isolates designated $\mathrm{HFJ}^{\mathrm{T}}$ is described in the present study. The $16 \mathrm{~S}$ rRNA gene sequence showed that it belongs to the genus Tenacibaculum (family Flavobacteriaceae, phylum 'Bacteroidetes') described by Suzuki et al. (2001). To date the genus comprises 21 species derived from a variety of marine environments and marine organisms (Kim et al. 2013; LPSN 2015). Several of the type strains in genus Tenacibaculum have been reported as pathogenic for fish or associated with disease in cultured marine fish (Wakabayashi et al. 1986; Hansen 
et al. 1992; Piñeiro-Vidal et al. 2008a, b; López et al. 2010; Piñeiro-Vidal et al. 2012). Tenacibaculum maritimum, the causative agent of marine tenacibaculosis, is the best known and most extensively studied fish pathogenic bacterium in the genus (Wakabayashi et al. 1986; Suzuki et al. 2001). The disease has been reported from Europe, Japan, North America and Australia and affects both wild and cultured fish, including Rainbow trout and Atlantic salmon (Toranzo et al. 2005; Avendaño-Herrera et al. 2006; Bruno et al. 2013). T. maritimum has never been isolated in cases of ulcerative disease in Norway (Olsen et al. 2011).

There has been a growing attention regarding the potential role of Norwegian Tenacibaculum spp. in causing ulcerative disease in sea-reared Atlantic salmon, as they are commonly identified from skin lesion in mixed cultures with the bacterium Moritella viscosa or as the apparent sole agent (Olsen et al. 2011; Born $\varnothing$ and Lie 2015). The aim of the present study was to determine the taxonomic position of the fish pathogenic Tenacibaculum strain $\mathrm{HFJ}^{\mathrm{T}}$ using genetic, phenotypic and chemotaxonomic characterisations, a detailed phylogenetic investigation based on 16S rRNA gene sequences and concatenated housekeeping (HK) gene sequences, and DNA-DNA hybridization (DDH).

\section{Materials and methods}

A total of 11 isolates from genus Tenacibaculum were included in the present study (Table 1). Strain $\mathrm{HFJ}^{\mathrm{T}}$ was isolated in spring 2013 from a skin lesion of a diseased Atlantic salmon at a seawater site in Finnmark, Norway. Tenacibaculum sp. strains Tsp. 2-7 were collected from skin or gill of Atlantic salmon and cod in Norway. The type strains Tenacibaculum dicentrarchi NCIMB $14598^{\mathrm{T}}$, Tenacibaculum ovolyticum NCIMB $13127^{\mathrm{T}}$, Tenacibaculum soleae NCIMB $14368^{\mathrm{T}}$ and T. maritimum NCIMB $2154^{\mathrm{T}}$ were obtained from The National Collection of Industrial, Marine and Food Bacteria (NCIMB). Subcultivation was performed on Marine agar (MA) (Difco 2216) plates at $16^{\circ} \mathrm{C}$ for $48 \mathrm{~h}$. The strains were preserved in CryoTube ${ }^{\mathrm{TM}}$ vials (Thermo scientific) at $-80{ }^{\circ} \mathrm{C}$.

Draft genome sequencing of strain $\mathrm{HFJ}^{\mathrm{T}}$ was carried out by BaseClear B.V (Leiden, The Netherlands.) using Illumina next generation sequencing on a HiSeq $2500^{\mathrm{TM}}$ platform. Extraction of the required concentration $(>100 \mathrm{ng} / \mu \mathrm{l})$ of genomic DNA was performed using an E.Z.N.A. tissue DNA kit ${ }^{\mathrm{TM}}$ (Omega Bio-Tek) following the cultured cells protocol. The draft genome sequence obtained for strain $\mathrm{HFJ}^{\mathrm{T}}$ was used for the PCR primer design using primer-BLAST (Ye et al. 2012) and to verify obtained sequences for strain $\mathrm{HFJ}^{\mathrm{T}}$.

Genomic DNA from all Tenacibaculum sp. strains listed in Table 1 was extracted using an E.Z.N.A. tissue DNA kit ${ }^{\mathrm{TM}}$ (Omega Bio-Tek) following the cultured cells protocol. PCR was performed using the $16 \mathrm{~S}$ rRNA primers $27 \mathrm{~F}$ and 1518R (Giovannoni et al. 1996) and specific primers for five HK genes (atpD, fusA, $p g k, r p o B$, and tuf) (Table 2). Amplification was based on a standard reaction mixture containing $2.5 \mu \mathrm{l}$

Table 1 List of Tenacibaculum strains included in the present study

\begin{tabular}{|c|c|c|c|c|c|}
\hline Bacterial species & Strain & Origin & Host & Tissue & Year \\
\hline Tenacibaculum sp. & $\mathrm{HFJ}^{\mathrm{T}}$ & Norway & Atlantic salmon & Skin & 2013 \\
\hline Tenacibaculum sp. & Tsp.2 & Norway & Atlantic salmon & Skin & 2013 \\
\hline Tenacibaculum sp. & Tsp.3 & Norway & Atlantic salmon & Gill & 2014 \\
\hline Tenacibaculum sp. & Tsp.4 & Norway & Atlantic salmon & Skin & 2013 \\
\hline Tenacibaculum sp. & Tsp.5 & Norway & Atlantic salmon & Skin & 2014 \\
\hline Tenacibaculum sp. & Tsp.6 & Norway & Atlantic salmon & Skin & 2009 \\
\hline Tenacibaculum sp. & Tsp.7 & Norway & Farmed Atlantic cod & Skin & 2009 \\
\hline Tenacibaculum maritimum & NCIMB $2154^{\mathrm{T}}$ & Japan & Red sea bream fingerling & Kidney & 1977 \\
\hline Tenacibaculum soleae & NCIMB $14368^{\mathrm{T}}$ & Spain & Senegalese sole & Unknown & 2007 \\
\hline Tenacibaculum ovolyticum & NCIMB $13127^{\mathrm{T}}$ & Norway & Atlantic halibut eggs & Eggs & 1989 \\
\hline Tenacibaculum dicentrarchi & NCIMB $14598^{\mathrm{T}}$ & Spain & European sea bass & Skin & 2009 \\
\hline
\end{tabular}

The Tenacibaculum sp. strains were collected from Norwegian field cases, whereas the type strains were obtained from NCIMB 
Table 2 List of PCR primers used in present study

\begin{tabular}{llll}
\hline Target gene & Name & Sequence $\left(5^{\prime}-3^{\prime}\right)$ & Source \\
\hline 16S rRNA & B27F & AGAGTTTGATCMTGGCTCAG & Giovannoni et al. (1996) \\
16S rRNA & A1518R & AAGGAGGTGATCCANCCRCA & Giovannoni et al. (1996) \\
tuf & Tb_tuf F1 & ACCTCCTTCACGGATAGC & Present study \\
tuf & Tb_tuf R1 & TTACGATCGTTCGAAGCCCC & Present study \\
$r p o B$ & Tb_rpoB F1 & ATYTCTCCAAAACGCTGACC & Present study \\
$r p o B$ & Tb_rpoB R1 & AAAACGAATCAAGGWACGAAYA & Present study \\
$r p o B$ & Tb_rpoB F2 & ACCCTTTCCAAGGCATAAAGG & Present study \\
$r p o B$ & Tb_rpoB R2 & GAGCCATYGGTTTTGAAAGAGA & Present study \\
$r p o B$ & Tb_rpoB F3 & CTCTTGCTGTCTCCTCATCTG & Present study \\
$r p o B$ & Tb_rpoB R3 & ATCCACCAAGATATAGCATCCA & Present study \\
pgk & Tb_pgk F1 & GCTCCWCCACCWGTAGAAAC & Present study \\
$p g k$ & Tb_pgk R1 & TYCGTGTAGATTTTAATGTGCCT & Present study \\
atpD & Tb_atpD F1 & TGGYCCAGTWATCGATGTTGA & Present study \\
atpD & Tb_atpD R1 & AATACGYTCTTGCATTGCTC & Present study \\
$f u s A$ & Tb_fusA F1 & ATGGTAACTCACCCATTCCAGA & Present study \\
$f u s A$ & Tb_fusA R1 & TGGCATGATGCAACACAAGG & Present study \\
\hline
\end{tabular}

Extra buffer, $1.25 \mathrm{mM}$ deoxyribonucleotide triphosphates, 0.75 units $(0.15 \mu \mathrm{L}) \mathrm{Taq}$ DNA polymerase (BioLabs, New England), $5 \mu \mathrm{M}(1 \mu \mathrm{L})$ of forward and reverse primers; DNase-RNase free water was added to a final volume of $25 \mu \mathrm{L}\left(16.85 \mu \mathrm{L} \mathrm{H} \mathrm{H}_{2} \mathrm{O}\right)$. Amplification was performed in a GeneAmp PCR system 2700 (Applied Biosystems) at $95^{\circ} \mathrm{C}$ for $5 \mathrm{~min} ; 35$ cycles of $95{ }^{\circ} \mathrm{C}$ for $30 \mathrm{~s}, 58{ }^{\circ} \mathrm{C}$ for $30 \mathrm{~s}, 72{ }^{\circ} \mathrm{C}$ for 60-100 s, followed by $72{ }^{\circ} \mathrm{C}$ for $10 \mathrm{~min}$. The PCR product was confirmed by gel electrophoresis and enzymatically purified using ExoStar 1-Step ${ }^{\circledR}$ (GE Healthcare Bio-Sciences Corp) in an Artik Thermal Cycler (Thermo Scientific) at $37{ }^{\circ} \mathrm{C}$ for $15 \mathrm{~min}$ and at $80{ }^{\circ} \mathrm{C}$ for $15 \mathrm{~min}$. The sequencing reaction was performed using a BigDye ${ }^{\circledR}$ version 3.1 reaction in an Arktik Thermal Cycler, at $96{ }^{\circ} \mathrm{C}$ for $5 \mathrm{~min} ; 30$ cycles of $96{ }^{\circ} \mathrm{C}$ for $10 \mathrm{~s}, 58{ }^{\circ} \mathrm{C}$ for $5 \mathrm{~s}$ and $60{ }^{\circ} \mathrm{C}$ for $4 \mathrm{~min}$. The reaction was composed of a mixture of $5.5 \mu \mathrm{L}$ deionized water, $1 \mu \mathrm{L}$ BigDye ${ }^{\circledR}$ Terminator 3.1 version sequencing buffer, $1 \mu \mathrm{L}$ BigDye Terminator 3.1 version Ready Reaction Premix (2.5X) (Invitrogen), $3.2 \mathrm{pmol}(1 \mu \mathrm{L})$ forward and reverse primers and $1.5 \mu \mathrm{L}$ purified PCR product. Sequencing was carried out by the Sequencing Facility at Høyteknologisenteret i Bergen (http://www.uib.no/seqlab). Samples were cleaned with Agencourt CleannSeq (Beckman Coulter, Inc.) before being sequenced in a 96-capillary 3730xl DNA Analyzer (Applied Biosystems). The software Vector NTI ${ }^{\circledR}$ v.9.0 (Invitrogen) was used to assemble and align the obtained sequences.

Three alignments were constructed for phylogenetic analysis. The first, 16S rRNA gene sequence alignment, consisted of 1341 positions and included sequences of $\mathrm{HFJ}^{\mathrm{T}}$ and the 21 published type strains in the genus Tenacibaculum. In this alignment, all sequences were obtained from GenBank with the exception of strain $\mathrm{HFJ}^{\mathrm{T}}, T$. dicentrarchi NCIMB $14598^{\mathrm{T}}$, T. ovolyticum NCIMB $13127^{\mathrm{T}}$, T. soleae NCIMB $14368^{\mathrm{T}}$ and T. maritimum NCIMB $2154^{\mathrm{T}}$. The second 16S rRNA gene sequence alignment of 1349 positions contained sequences from all strains listed in Table 1. A third alignment, of 6750 positions, was constructed using concatenated sequences of the five $\mathrm{HK}$ genes of the strains listed in Table 1; atpD at position 1-807, fusA at position 808-1575, pgk at position 1576-2511, rpoB at position 2512-5778 and tuf at position 5779-6750. All sequences obtained in the present study are available in GenBank with accession numbers presented in Table 3. Alignments were constructed in AlignX in the Vector $\mathrm{NTI}^{\circledR}$ v.9.0 (Invitrogen) software package before sequences were adjusted to equal length and correct reading frames in GeneDoc (Nicholas et al. 1997). Concatenation of the HK alignments was performed using KAKUSAN4 (Tanabe 2011). The best fitted evolutionary model for each alignment was calculated using Mega 6 (Tamura et al. 2013). For the Bayesian analysis of the 
Table 3 List of GenBank accession numbers of sequences obtained in the present study

\begin{tabular}{|c|c|c|c|c|c|c|}
\hline Bacterial species/strain & $16 \mathrm{~S}$ rRNA & atpD & fusA & $p g k$ & $r р о B$ & tuf \\
\hline T. finnmarkense sp.nov $\mathrm{HFJ}^{\mathrm{T}}$ & KT270385 & KT270377 & KT270369 & KT270424 & KT270410 & KT270399 \\
\hline T. dicentrarchi $\mathrm{NCIMB} 14598^{\mathrm{T}}$ & KT270381 & KT270375 & KT270364 & KT270421 & KT270408 & KT270402 \\
\hline T. maritimum NCIMB $2154^{\mathrm{T}}$ & KT270382 & KT270378 & KT270366 & KT270416 & KT270411 & KT270393 \\
\hline T. ovolyticum NCIMB $13127^{\mathrm{T}}$ & KT270383 & KT270379 & KT270367 & KT270423 & KT270412 & KT270395 \\
\hline T. soleae NCIMB $14368^{\mathrm{T}}$ & KT270384 & KT270380 & KT270368 & KT270417 & KT270413 & KT270394 \\
\hline Tenacibaculum sp. Tsp. 2 & KT270386 & KT270376 & KT270365 & KT270420 & KT270409 & KT270400 \\
\hline Tenacibaculum sp. Tsp. 3 & KT270387 & KT270373 & KT270362 & KT270422 & KT270406 & KT270397 \\
\hline Tenacibaculum sp. Tsp.4 & KT270388 & KT270370 & KT270359 & KT270414 & KT270403 & KT270392 \\
\hline Tenacibaculum sp. Tsp.5 & KT270389 & KT270371 & KT270360 & KT270418 & KT270404 & KT270398 \\
\hline Tenacibaculum sp. Tsp.6 & KT270390 & KT270372 & KT270361 & KT270415 & KT270405 & KT270396 \\
\hline Tenacibaculum sp. Tsp.7 & KT270391 & KT270374 & KT270363 & KT270419 & KT270407 & KT270401 \\
\hline
\end{tabular}

concatenated HK alignment, KAKUSAN4 was used for calculation of substitution rate and the best fit model for the individual loci and codon positions and exported into a Mr. Bayes-block. A phylogenetic analysis of all three alignments were conducted using the Maximum Likelihood (ML) method with the best fitted evolutionary model, 1000 bootstrap replications and default settings in Mega 6. The BEAST package v1.8 (Drummond and Rambaut 2007) was used for Bayesian analysis of the two 16S rRNA gene datasets using the best fitted model, relaxed lognormal molecular clock and a mcmc of 100000000 generations. The Bayesian phylogenetic analysis of the HK gene dataset was conducted in Mr.Bayes V.3.2.2 (Ronquist et al. 2012) using the data block with the proportional codon proportional, model from KAKUSAN4 and a memc of 67000000 generations. Kordia algicida (GenBank accession nr: AB681152) was used as outgroup in the 16S rRNA phylogenetic analysis that included all the type strains, while $T$. maritimum NCIMB $2154^{\mathrm{T}}$ was used as outgroup in the other phylogenetic analysis. The phylograms for the ML analysis were constructed in Mega 6. The Effective sample size values (ESS) in the Bayesian analysis were inspected using Tracer ver. 1.6 (Rambaut et al. 2014). All ESS values were within the recommended range (above 200) for all parameters. A maximum clade credibility tree was obtained using a $10 \%$ burnIn in Tree-Annotator and viewed using FigTree (Drummond et al. 2012). For 16S rRNA gene sequence similarity analysis, Percent Nucleotide Identity (PNI) was calculated using the distance matrix option in BioEdit (Hall 2011). In the Average
Nucleotide Identity (ANI) calculations, the sequences from the concatenated HK gene alignment for all strains listed in Table 1 were uploaded and analysed using the Average Nucleotide Identify option in EzGenome (Kim et al. 2012).

Morphological, physiological and biochemical tests were performed as described by Bernardet et al. (2002) for strain $\mathrm{HFJ}^{\mathrm{T}}$ and the phylogenetically closely related type strains $T$. dicentrarchi NCIMB $14598^{\mathrm{T}}$ and T. ovolyticum NCIMB $13127^{\mathrm{T}}$ as reference strains. All tests were performed on cultures incubated at $16{ }^{\circ} \mathrm{C}$ for $48 \mathrm{~h}$ unless otherwise stated. Colony shape, margin, elevation, size, texture, appearance, pigmentation and optical property were examined as described by Smibert and Krieg (1994). The ability to stick to agar and viscosity of the colonies was also investigated. Cell morphology was investigated using scanning electron microscopy (SEM), transmission electron microscopy (TEM) and light microscopy. Gliding motility was determined by phase contrast microscopic examination of a Marine broth (MB) (Difco 2216) culture by the hanging drop technique as recommended by Bernardet et al. (2002). Presence of flexirubin type pigments was determined by the bathochromic shift test using a $20 \%$ (w/v) KOH solution (Fautz and Reichenbach 1980). Congo red absorption was tested as described by Bernardet et al. (2002). The Gram reaction were performed with a Fluka 77730 Gram Staining Kit (Fluka ${ }^{\circledR}$ analytical) following the manufacturer's protocol and the non-staining $\mathrm{KOH}$ method (Buck 1982). The Voges-Proskauer reaction was performed as described by Piñeiro-Vidal et al. (2012). Oxidase 
activity and ability to split indole from tryptophan was tested using $\mathrm{BBL}^{\mathrm{TM}}$ DrySlide Oxidase and $\mathrm{BBL}^{\mathrm{TM}}$ DrySlide Indole (BD BBL ${ }^{\mathrm{TM}}$, U.S.A), following the manufacturer's protocol. Catalase activity was examined using the slide (drop) method following the protocol by Reiner (2010). Growth under anaerobic conditions was tested on MA using the GasPak anaerobic system (BBL). Production of $\mathrm{H}_{2} \mathrm{~S}$ was detected by taping a lead acetate impregnated paper strip (Sigma) to the inside of the lid of MA plates, using Parafilm to seal lid and plate. The plates were incubated at $16{ }^{\circ} \mathrm{C}$ for 6 days. Growth on blood agar was tested using blood agar containing $2 \% \mathrm{NaCl}$ (BAS) (Microbial laboratory, Haukeland University Hospital, Bergen). Degradation of starch (1\% w/v), casein $(1 \% \mathrm{w} / \mathrm{v})$, and Tween $80(1 \% \mathrm{v} / \mathrm{v})$ was investigated on MA. MB supplemented with gelatin $(1 \% \mathrm{w} / \mathrm{v})$ was used to investigate degradation of gelatin. Utilisation of carbon sources was tested on basal agar medium $\left[0.2 \mathrm{~g} \mathrm{NaNO}_{3}, 0.2 \mathrm{~g} \mathrm{NH} \mathrm{NH}_{4} \mathrm{Cl}\right.$, $0.05 \mathrm{~g}$ yeast extract, $15 \mathrm{~g}$ agar and $36 \mathrm{~g}$ red sea salt (Red Sea)] per liter distilled water containing $0.4 \%$ carbon source $[\mathrm{D}(+)$-sucrose, $\mathrm{D}(-)$-ribose, $\mathrm{D}(+)$ galactose, D-glucose, L-proline, L-glutamate, L-tyrosine] as described by (Suzuki et al. 2001). Absence of growth after one month of incubation was recorded as negative. Other enzymatic reactions were evaluated in the API ZYM system (bioMerieux) following the manufacturer's instructions, except that sterile seawater was used as suspension medium. Growth at $\mathrm{pH}$ 4-10 (at unit intervals) was assessed in $\mathrm{MB}$; $\mathrm{pH}$ was adjusted using $1 \mathrm{M} \mathrm{NaOH}$ and $1 \mathrm{M} \mathrm{HCl}$. The temperature range for growth was determined on MA plates incubated at 2, 4, 8, 16, 20, 25, 30 and $37{ }^{\circ} \mathrm{C}$ for 7 days. Salinity requirement was determined with saltless MA [per liter distilled water: $5.0 \mathrm{~g}$ peptone, $1 \mathrm{~g}$ yeast extract and $0.1 \mathrm{~g}$ ferric citrate] containing $10,20,30,50,70$ and $100 \%$ strength seawater $(100 \%$ seawater $=38.2 \mathrm{~g} / \mathrm{L}$ red sea salt) or 0.8, 1.0, 3.0, 5.0, 7.0 and $10.0 \%$ (w/v) $\mathrm{NaCl}$ (Sigma). Sensitivity to antimicrobials was evaluated by the disc diffusion method following the procedures of The Clinical and Laboratory Standards Institute (CLSI 2005), except that the plates were incubated at $16{ }^{\circ} \mathrm{C}$ for 10 days on MA plates due to reduced growth for some strains on the recommended Flexibacter Maritimus Medium (FMM). The tests were performed using commercial discs (Neo-sensitabs ${ }^{\mathrm{TM}}$ and Sensi-disc ${ }^{\mathrm{TM}}$ ) containing kanamycin $(500 \mu \mathrm{g}), \quad$ streptomycin $\quad(10 \mu \mathrm{g})$, gentamicin $(30 \mu \mathrm{g})$, trimethoprim + sulfamethoxazole $(125+2375 \mu \mathrm{g})$, ceftazidime $(30 \mu \mathrm{g})$, ciprofloxacin $(5 \mu \mathrm{g})$, pipemidic acid $(30 \mu \mathrm{g})$, cefuroxime $(30 \mu \mathrm{g})$, penicillin $\mathrm{G}(1 \mathrm{U})$, ampicillin $(2 \mu \mathrm{g})$, tetracycline $(30 \mu \mathrm{g})$, erythromycin $(15 \mu \mathrm{g})$, florfenicol $(30 \mu \mathrm{g})$, oxolinic acid $(10 \mu \mathrm{g})$ and oxytetracycline $(30 \mu \mathrm{g})$. Several of the tests described above were also performed for the other strains included in the present study, except Tsp.7. Strain Tsp.7 was uncultivable after prolonged cryo-storage and was therefore not included in the phenotypic tests.

The following chemotaxonomic and genetic analyses were carried out by the Identification Service of the DSMZ (Braunschweig, Germany): DNA G+C content, DDH, menaquinone and fatty acid methyl ester analysis. All strains were grown in MB at $16^{\circ} \mathrm{C}$ for $48 \mathrm{~h}$, except for the DDH test. For DDH, cells were grown in $\mathrm{MB}$ at $16{ }^{\circ} \mathrm{C}$ for $72 \mathrm{~h}$ and the obtained bacterial biomass washed twice in $1 \times$ Phosphate Buffered Saline. The cells were disrupted using a Constant Systems TS 0.75 KW (IUL Instruments, Germany) and the DNA in the crude lysate purified by chromatography on hydroxyapatite as described by Cashion et al. (1977). DDH was carried out as described by Ley et al. (1970) under consideration of the modifications described by Huss et al. (1983) using a model Cary 100 Bio UV/VIS-spectrophotometer equipped with a Peltier-thermostatted $6 \times 6$ multicell changer and a temperature controller with in situ temperature probe (Varian). Extraction of fatty acid methyl esters, washing of extracts and GC analysis were performed by using the Sherlock MIS (MIDI Inc, Newark, USA) system using the MIDI Sherlock version 6.1 and TSBA40 database.

\section{Results and discussion}

A polyphasic approach that integrates phenotypic data with genetic and phylogenetic data was performed in the current study. This approach is recommended by several authors for bacterial taxonomic investigations (Bernardet et al. 2002; Tindall et al. 2010). As it has been regarded as best practice to include more than one representative strain when describing a novel taxon, several Tenacibaculum sp. strains (Tsp.2-7) obtained from Norwegian mariculture were included in the present study. Strains HFJ ${ }^{\mathrm{T}}$ and Tsp. 2 have been shown to be pathogenic to Atlantic salmon 


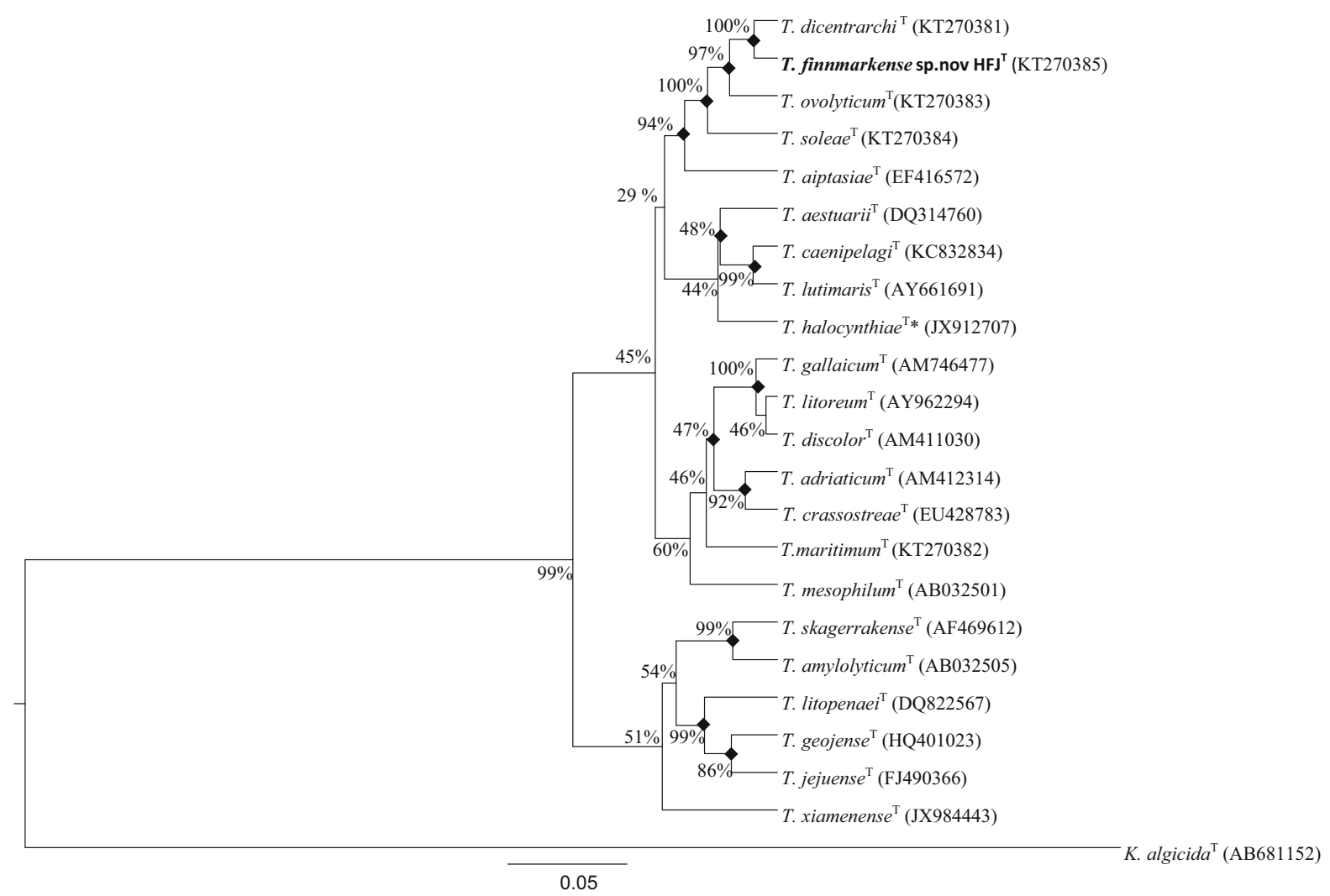

Fig. 1 The relationship of the novel species $T$. finnmarkense sp. nov $\mathrm{HFJ}^{\mathrm{T}}$ and the 21 type strains in genus Tenacibaculum $i^{*}=$ quotation marks denote names that have not been validly published) based on the 16S rRNA gene sequences, using Kordia algicida $^{\mathrm{T}}$ as outgroup. The phylogenetic analysis was inferred using the Bayesian method with the best fitted evolutionary

reproducing the clinical signs in a challenge study in 2013 (Vold 2014). The bacteria were re-isolated and their identity confirmed by sequencing of the $16 \mathrm{~S}$ rRNA gene, thus fulfilling Koch's postulates.

The phylogenetic analysis based on the 16S rRNA gene sequences and the concatenated HK gene sequences (Fig. 1, 2, 3) showed that strains $\mathrm{HFJ}^{\mathrm{T}}$, Tsp.2, Tsp.5 and Tsp.7 belong to a distinct clade separate from the closely related type strains in the genus Tenacibaculum. Moreover, the analysis showed that strain Tsp. 4 forms a clade with $T$. dicentrarchi NCIMB $14598^{\mathrm{T}}$ and Tsp.6 forms a clade with $T$. ovolyticum NCIMB $13127^{\mathrm{T}}$, while the phylogenetic placement of strain Tsp. 3 is uncertain. These clades were evident in all phylogenetic trees using both the Bayesian and ML method. All phylogenetic trees model $(\mathrm{GTR}+\mathrm{G}+\mathrm{I})$. The posterior probability is presented next to each node in percentage. There were a total of 1341 positions in the dataset. Evolutionary analyses were conducted using BEAST package v1.8. Shared nodes identified in corresponding ML analysis are marked with filled squares. Accesion numbers are in parentheses. Scale bar 0.05 substiutions per site

showed that strain $\mathrm{HFJ}^{\mathrm{T}}$ is closely related to $T$. dicentrarchi NCIMB $14598^{\mathrm{T}}$, both belonging to distinct clades.

As strain $\mathrm{HFJ}^{\mathrm{T}}$ showed more than $97 \%$ 16S rRNA gene sequence similarity (PNI) to $T$. dicentrarchi NCIMB $14598^{\mathrm{T}}$ (Table 4), DDH was performed as recommended (Stackebrandt and Goebel 1994; Tindall et al. 2010). The DDH tests revealed that the DNA relatedness of strain $\mathrm{HFJ}^{\mathrm{T}}$ was 54.8 (52.0) \% to $T$. dicentrarchi NCIMB $14598^{\mathrm{T}}$ and 36.6 (39.7) \% to $T$. ovolyticum NCIMB $13127^{\mathrm{T}}$. Results from repeated tests are shown in parentheses. When considering the threshold value of $70 \%$ DNA-DNA similarity for delineation of bacterial species proposed by the ad hoc committee (Wayne et al. 1987), strain $\mathrm{HFJ}^{\mathrm{T}}$ does not belong to the species T. dicentrarchi NCIMB $14598^{\mathrm{T}}$ 


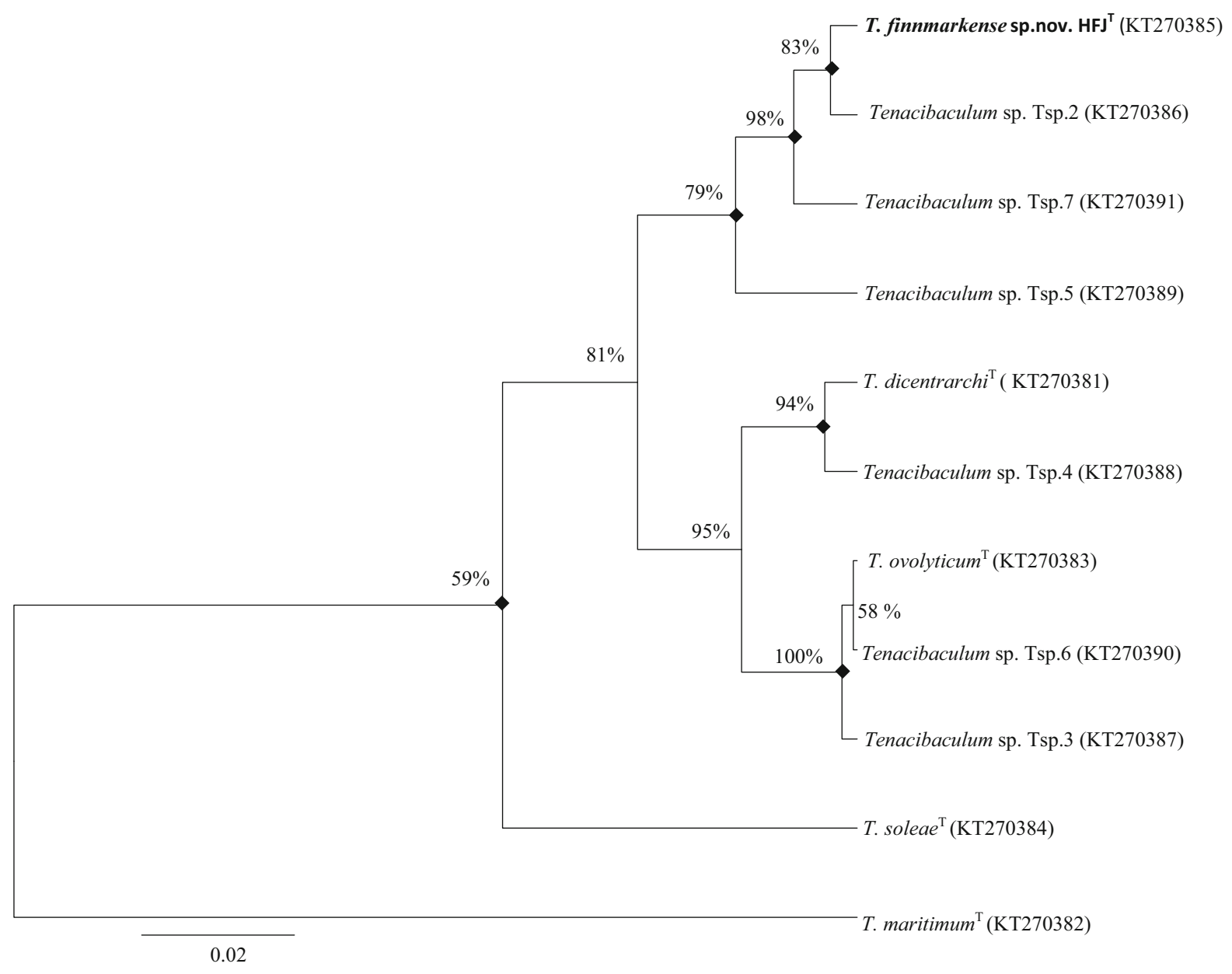

Fig. 2 The relationship of the novel species $T$. finnmarkense sp.nov $\mathrm{HFJ}^{\mathrm{T}}$, Tenacibaculum sp. strains Tsp. 2-7 and the three closest related type strains based on 16S rRNA gene sequences, using T. maritimum NCIMB $2154^{\mathrm{T}}$ as outgroup. The phylogenetic analysis was inferred using the Bayesian method with the best fitted evolutionary model $(\mathrm{HKY}+\mathrm{G}+\mathrm{I})$. The posterior

or T. ovolyticum NCIMB $13127^{\mathrm{T}}$. It is generally accepted that an ANI value of 95-96\% corresponds to a DDH threshold value of $70 \%$ and can be used as a boundary for species delineation (Goris et al. 2007; Richter and Rosselló-Móra 2009). Furthermore, a study by Kim et al. (2014) revealed that a PNI of 98.65\% corresponded to an ANI value of 95-96\%. The calculated ANI and PNI values between strain $\mathrm{HFJ}^{\mathrm{T}}$ and $T$. dicentrarchi NCIMB $14598^{\mathrm{T}}$ were 94.6 and $97.2 \%$ respectively. By applying both the ANI and PNI threshold on all 11 strains included in this study (Table 4) we found that strains $\mathrm{HFJ}^{\mathrm{T}}$, Tsp.2, probability is presented next to each node in percentage. There were a total of 1349 positions in the dataset. Evolutionary analyses were conducted using BEAST package v1.8. Shared nodes identified in corresponding ML analysis are marked with filled squares. Accesion numbers are in parentheses. Scale bar 0.02 substitutions per site

Tsp.5 and Tsp.7 belong to the same species; Tsp.4 belongs to the species $T$. dicentrarchi, while Tsp.6 belongs to the species $T$. ovolyticum. These findings correspond to results from the phylogenetic analysis and underpin that strain $\mathrm{HFJ}^{\mathrm{T}}$ represents a novel species in genus Tenacibaculum.

Cells of strain $\mathrm{HFJ}^{\mathrm{T}}$ were observed to be rodshaped, $0.5 \mu \mathrm{m}$ wide and $5-25 \mu \mathrm{m}$ in length and Gram-stain negative. Considerably longer filamentous cells and spherical degenerative cells were frequently observed in older cultures. A rapid decrease in viability was found to occur with prolonged 


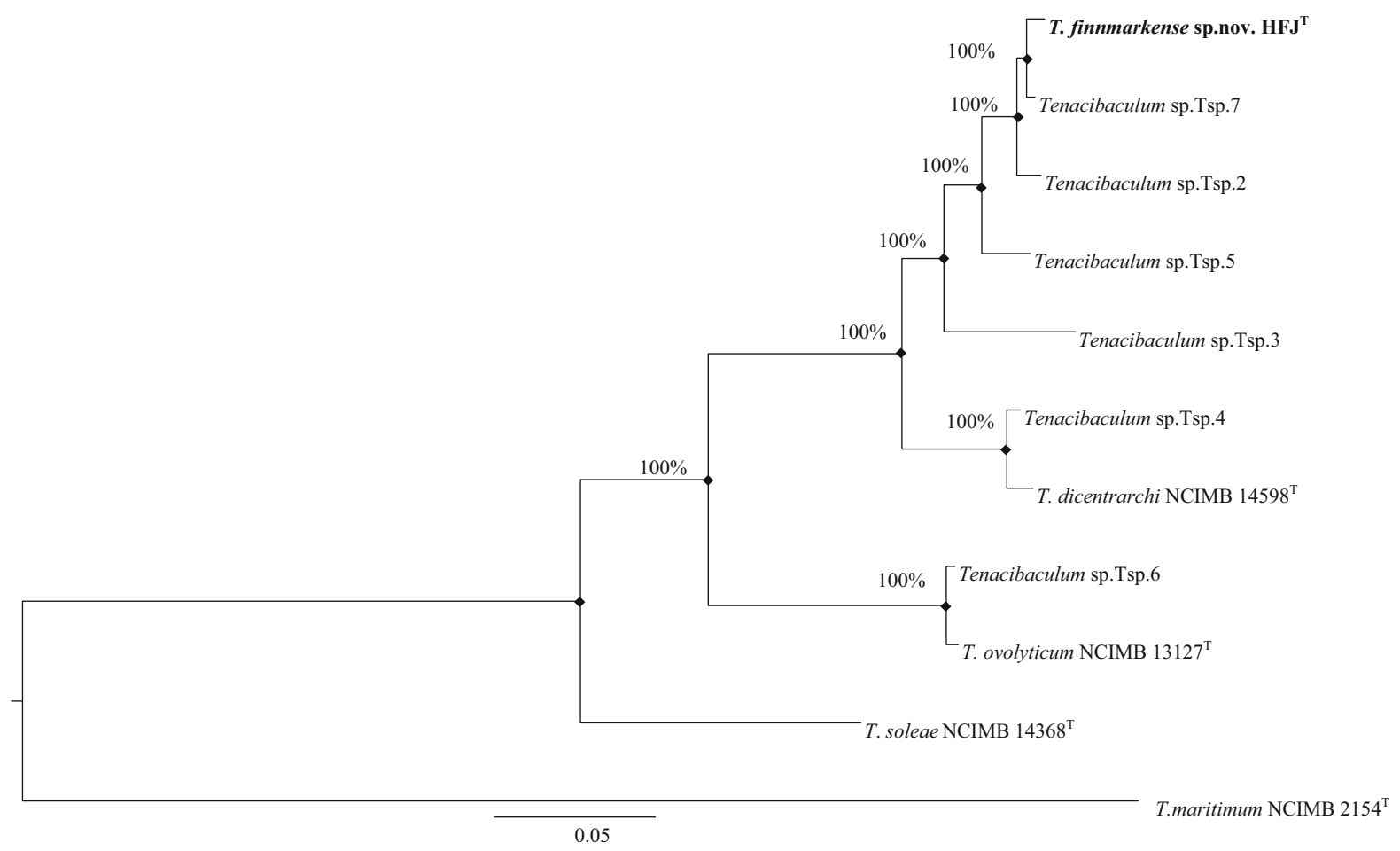

Fig. 3 The relationship of the novel species T. finnmarkense sp.nov $\mathrm{HFJ}^{\mathrm{T}}$, Tenacibaculum sp. strains Tsp. 2-7 and the three closest related type strains based on a concatenated sequences of five $\mathrm{HK}$ genes (atpD at position 1-807, fusA at position 808-1575, pgk at position 1576-2511, rрoB at position 2512-5778 and tuf at position 5779-6750), using T. maritimum ${ }^{\mathrm{T}}$ as outgroup. The accession numbers for the HK genes used in the concatenated dataset are presented in Table 3. The phylogenetic

incubation ( $>96 \mathrm{~h})$. Differential phenotypic characteristics between all strains listed in Table 1, except strain Tsp.7, are summarised in Table 5 and are included in the species description. The $\mathrm{G}+\mathrm{C}$ content of strain $\mathrm{HFJ}^{\mathrm{T}}$ was determined to be $34.1 \mathrm{~mol} \%$ which is within the range reported for other type strains in the genus Tenacibaculum (29.8-35.2 mol\%). The major fatty acids ( $>5 \%$ of the total fatty acids) for strain $\mathrm{HFJ}^{\mathrm{T}}$ were identified as summed feature 3 (comprising $\mathrm{C}_{16: 1} \omega 7 \mathrm{c}$ and/or iso- $\mathrm{C}_{15: 0} 2-\mathrm{OH}$ ), iso- $\mathrm{C}_{15: 0}$, anteiso-

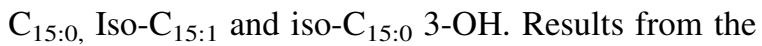
fatty acid analysis for strain $\mathrm{HFJ}^{\mathrm{T}}$ and $T$. dicentrarchi NCIMB $14598^{\mathrm{T}}$ are listed in Table 6 . The respiratory quinone was identified as menaquinone $6(100 \%)$ while flexirubin-type pigments were found to be absent. This is in accordance with the chemotaxonomic characteristics of the members of the genus Tenacibaculum (Suzuki et al. 2001). In the API ZYM analysis was inferred using the Bayesian method with the best fitted evolutionary model. The posterior probability is presented next to each node in percentage. There were a total of 6750 positions in the dataset. Evolutionary analyses were conducted using KAKUSAN4 and Mr.Bayes. Shared nodes identified in corresponding ML analysis are marked with filled squares. Scale bar 0.05 substitutions per site

system, alkaline phosphatase, esterase (C4), esterase lipase (C8), leucine arylamidase, valine arylamidase, cystein arylamidase, acid phosphatase and naphtholAS-BI-phosphohydrolase were found to be present. Lipase (C14), trypsin, $\alpha$-chymotrypsin and all enzymes related to the metabolism of carbohydrates were found to be absent. Strain $\mathrm{HFT}^{\mathrm{T}}$ was found to be susceptible to trimethoprim-sulfamethoxazole, ceftazidime, ciprofloxacin, pipemidic acid, cefuroxime, penicillin G, ampicillin, tetracycline, erythromycin, florfenicol, oxytetracycline and oxolinic acid, but resistant to kanamycin, gentamicin and streptomycin.

Results from the phenotypic and chemotaxonomic tests show that strain $\mathrm{HFJ}^{\mathrm{T}}$ differs significantly from $T$. dicentrarchi NCIMB $14598^{\mathrm{T}}$ and T. ovolyticum NCIMB $13127^{\mathrm{T}}$ (Table 5). The fatty acid composition analysis (Table 6) shows that strain $\mathrm{HFJ}^{\mathrm{T}}$ has a very similar profile compared to that of $T$. dicentrarchi 


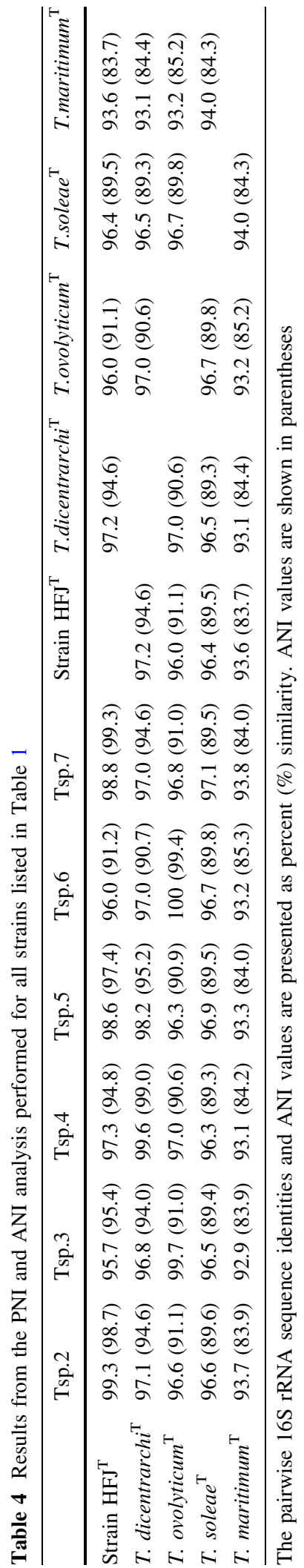

NCIMB $14598^{\mathrm{T}}$. Moreover, the $\mathrm{G}+\mathrm{C}$ content of strain $\mathrm{HFJ}^{\mathrm{T}}$ is higher than those reported for T. dicentrarchi NCIMB $14598^{\mathrm{T}}$ and T. ovolyticum NCIMB $13127^{\mathrm{T}}$. Strain $\mathrm{HFJ}^{\mathrm{T}}$ and T. ovolyticum NCIMB $13127^{\mathrm{T}}$ do not grow on BAS, in contrast to $T$. dicentrarchi NCIMB $14598^{\mathrm{T}}$. T. ovolyticum NCIMB $13127^{\mathrm{T}}$ is positive for the enzymes trypsin and $\mathrm{N}$-acetyl-glucosaminidase, while strain $\mathrm{HFJ}^{\mathrm{T}}$ and $T$. dicentrarchi $\mathrm{NCIMB} 14598^{\mathrm{T}}$ are negative. T. ovolyticum NCIMB $13127^{\mathrm{T}}$ was unique in being resistant to the antimicrobial drugs ceftazidime, penicillin $\mathrm{G}$ and ampicillin. The above mentioned differences further support strain $\mathrm{HFJ}^{\mathrm{T}}$ as representative of a novel species in the genus Tenacibaculum. Cell length was the only characteristic shown to correspond to the three clades inferred in the phylogenetic analysis. Results showed a length of 2-40 $\mu \mathrm{m}$ for strain Tsp. 4 and T. dicentrarchi NCIMB $14598^{\mathrm{T}}, 2-30 \mu \mathrm{m}$ for strains $\mathrm{HFJ}^{\mathrm{T}}$, Tsp.2, and Tsp.5, and $2-15 \mu \mathrm{m}$ for strain Tsp.6 and T. ovolyticum NCIMB $13127^{\mathrm{T}}$.

In conclusion, the differential genetic, phylogenetic, phenotypic and chemotaxonomic data presented shows that strain $\mathrm{HFJ}^{\mathrm{T}}$ should be classified as a novel species in genus Tenacibaculum, for which the name Tenacibaculum finnmarkense sp.nov. is proposed. This novel species also includes strains Tsp.2 and Tsp.5.

Description of Tenacibaculum finnmarkense sp. nov.

Tenacibaculum finnmarkense (finn.mark.en'se. N.L. neut.adj. finnmarkense of Finnmark, Norway, referring to the place of isolation).

Cells are strictly aerobic, Gram-stain negative, straight rods, $0.5 \mu \mathrm{m}$ in diameter and $2-30 \mu \mathrm{m}$ in length (filamentous cells $>100 \mu \mathrm{m}$ long may occur in older cultures) and motile by gliding. Degenerative spherical cells are observed in ageing cultures. Colonies on MA are circular, convex, pale yellow or yellow pigmented with translucent edges, have entire and/or undulating margins and a smooth texture with a shiny and sometimes nacreous appearance. The colonies are slightly viscous and do not stick to agar. Congo red absorption is negative. Growth occurs in media containing 50-100\% strength seawater but not in media supplemented with $\mathrm{NaCl}$ only. No growth occurs on BAS. Growth occurs at $2,4,8,16$ and $20^{\circ} \mathrm{C}$, but not at 25,30 and $37^{\circ} \mathrm{C}$. Growth occurs at $\mathrm{pH}$ 


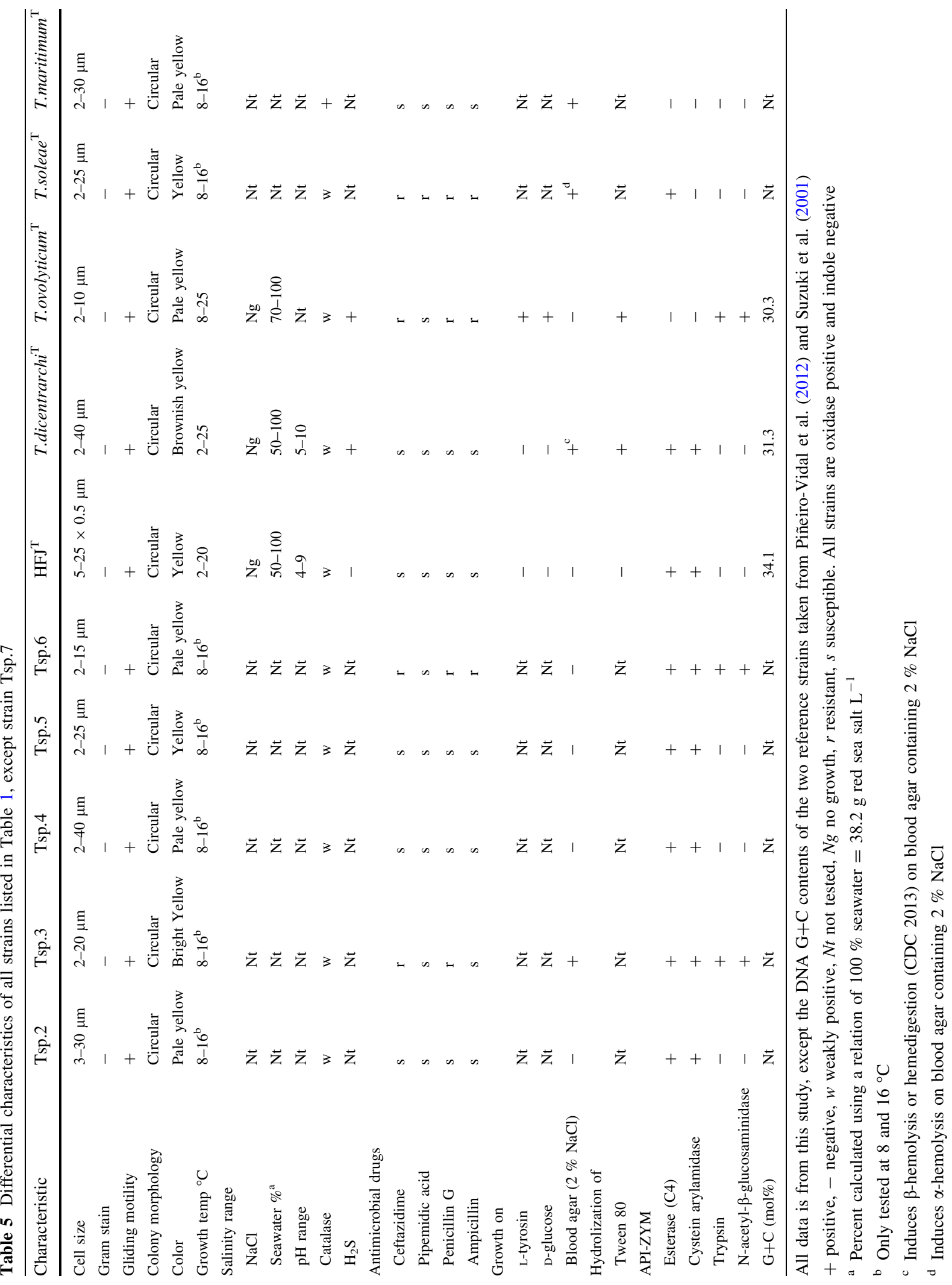


Table 6 Cellular fatty acid composition $(\%)$ of strain $\mathrm{HFJ}^{\mathrm{T}}$ and $T$. dicentrarchi NCIMB $14598^{\mathrm{T}}$

\begin{tabular}{|c|c|c|}
\hline Fatty acid & 1 & 2 \\
\hline \multicolumn{3}{|l|}{ Straight chain } \\
\hline $\mathrm{C}_{14: 0}$ & 1.3 & 1.0 \\
\hline $\mathrm{C}_{15: 0}$ & 1.8 & 3.8 \\
\hline \multicolumn{3}{|l|}{ Branched chain } \\
\hline iso- $\mathrm{C}_{13: 0}$ & 1.3 & 1.3 \\
\hline iso- $\mathrm{C}_{14: 0}$ & 1.6 & 2.5 \\
\hline iso- $\mathrm{C}_{15: 0}$ & 17.1 & 15.2 \\
\hline anteiso- $\mathrm{C}_{15: 1}$ & 17.7 & 13.3 \\
\hline iso- $\mathrm{C}_{15: 1}$ & 9.5 & 9.0 \\
\hline anteiso- $\mathrm{C}_{15: 1}$ & 1.9 & 1.9 \\
\hline iso- $\mathrm{C}_{16: 0}$ & $\operatorname{Tr}$ & 1.0 \\
\hline iso- $\mathrm{C}_{16: 1}$ & $\operatorname{Tr}$ & 2.8 \\
\hline \multicolumn{3}{|l|}{ Unsaturated } \\
\hline $\mathrm{C}_{15: 1} \omega 6 \mathrm{c}$ & 3.3 & 3.1 \\
\hline $\mathrm{C}_{16: 1} \omega 5 \mathrm{c}$ & 1.8 & 1.6 \\
\hline $\mathrm{C}_{17: 1} \omega 6 \mathrm{c}$ & $\operatorname{Tr}$ & 2.0 \\
\hline \multicolumn{3}{|l|}{ Hydroxylated } \\
\hline iso- $\mathrm{C}_{15: 0} 3-\mathrm{OH}$ & 12.4 & 11.6 \\
\hline $\mathrm{C}_{15: 0} 2-\mathrm{OH}$ & 1.0 & 1.3 \\
\hline $\mathrm{C}_{15: 0} 3-\mathrm{OH}$ & 1.5 & 2.2 \\
\hline iso- $\mathrm{C}_{16: 0} 3-\mathrm{OH}$ & 2.9 & 5.3 \\
\hline $\mathrm{C}_{16: 0} 3-\mathrm{OH}$ & 4.0 & 3.8 \\
\hline iso- $\mathrm{C}_{17: 0} 3-\mathrm{OH}$ & 2.4 & 2.7 \\
\hline Summed feature $3^{\mathrm{a}}$ & 9.5 & 10.3 \\
\hline
\end{tabular}

Strains $1 \mathrm{HFJ}^{\mathrm{T}}, 2$ T. dicentrarchi NCIMB $14598^{\mathrm{T}}$

All data are from this study. Fatty acids amounting to $<1 \%$ of the total fatty acids in all strains are not shown. Tr, Trace $(<1 \%)$

a Summed feature are groups of two or three fatty acids that cannot be separated by GLC using the MIDI system. Summed feature 3 comprises $\mathrm{C}_{16: 1} \omega 7 \mathrm{c}$ and/or iso- $\mathrm{C}_{15: 0} 2-\mathrm{OH}$

4.0-9.0 (optimum pH 6-8). Catalase and cytochrome oxidase activities are present. Gelatin and casein are hydrolysed, but Tween 80 and starch are not. The Voges-Proskauer and flexirubin tests are negative. No anaerobic growth is observed. $\mathrm{H}_{2} \mathrm{~S}$ and indole are not produced. L-Proline and L-glutamate are utilised but $\mathrm{D}(+)$-sucrose, $\mathrm{D}(-)$-ribose, $\mathrm{D}(+)$-galactose, $\mathrm{D}(+)$-glucose and L-tyrosine are not. The major fatty acids ( $>5 \%$ of the total fatty acids) are summed feature 3 (comprising $\mathrm{C}_{16: 1} \omega 7 \mathrm{c}$ and/or iso- $\mathrm{C}_{15: 0} 2-\mathrm{OH}$ ), iso$\mathrm{C}_{15: 0}$, anteiso- $\mathrm{C}_{15: 0}$, Iso- $\mathrm{C}_{15: 1}$ and iso- $\mathrm{C}_{15: 0} 3-\mathrm{OH}$. The respiratory quinone is menaquinone 6 . The DNA G+C content of the type strain is $34.1 \mathrm{~mol} \%$.

The type strain is $\mathrm{HFJ}^{\mathrm{T}}\left(=\mathrm{DSM} 28541^{\mathrm{T}}=\mathrm{NCIMB}\right.$ $\left.42386^{\mathrm{T}}\right)$, isolated from diseased Atlantic salmon (Salmo salar L.) in Norway. The GenBank accession number for the 16S rRNA gene sequence of strain $\mathrm{HFJ}^{\mathrm{T}}$ is $\mathrm{KT} 270385$.

Acknowledgments This study was partially funded by The Research Council of Norway (Project nr: 241364/O30) and Cermaq Norway.

\section{Compliance with ethical standards}

Conflict of interest The authors declare that they have no conflict of interest.

Open Access This article is distributed under the terms of the Creative Commons Attribution 4.0 International License (http:// creativecommons.org/licenses/by/4.0/), which permits unrestricted use, distribution, and reproduction in any medium, provided you give appropriate credit to the original author(s) and the source, provide a link to the Creative Commons license, and indicate if changes were made.

\section{References}

Avendaño-Herrera R, Toranzo AE, Magariños B (2006) Tenacibaculosis infection in marine fish caused by $T e$ nacibaculum maritimum: a review. Dis Aquat Org 71:255-266

Bernardet J-F, Nakagawa Y, Holmes B (2002) Proposed minimal standards for describing new taxa of the family Flavobacteriaceae and emended description of the family. Int J Syst Evolut Microbiol 52:1049-1070. doi:10.1099/ijs. 0.02136-0

Bornø G, Lie LM (2015) Fish health report 2014. The Norwegain Veterinary Institute, Harstad

Bruno DW, Noguera PA, Poppe TT (2013) A color Atlas of salmonid diseases, 2nd edn. Springer, Dordrecht

Buck JD (1982) Nonstaining (KOH) method for determination of gram reactions of marine bacteria. Appl Environ Microbiol 44:992-993

Cashion P, Holder-Franklin MA, McCully J, Franklin M (1977) A rapid method for the base ratio determination of bacterial DNA. Anal Biochem 81:461-466. doi:10.1016/00032697(77)90720-5

CLSI (2005) Methods for antimicrobial disc suseptibility testing of bacteria isolated from aquatic animals; proposed guidelines. Clinical and Laboratory standards institute M42-P Vol.25 No. 21

Drummond A, Rambaut A (2007) BEAST: Bayesian evolutionary analysis by sampling trees. BMC Evol Biol 7:214

Drummond AJ, Suchard MA, Xie D, Rambaut A (2012) Bayesian phylogenetics with BEAUti and the BEAST 1.7. Mol Biol Evol 29:1969-1973. doi:10.1093/molbev/mss075 
Fautz E, Reichenbach H (1980) A simple test for flexirubin-type pigments. FEMS Microbiol Lett 8:87-91. doi:10.1111/j. 1574-6968.1980.tb05056.x

Giovannoni SJ, Rappé MS, Vergin KL, Adair NL (1996) 16S rRNA genes reveal stratified open ocean bacterioplankton populations related to the Green Non-Sulfur bacteria. Proc Natl Acad Sci 93:7979-7984

Goris J, Konstantinidis KT, Klappenbach JA, Coenye T, Vandamme P, Tiedje JM (2007) DNA-DNA hybridization values and their relationship to whole-genome sequence similarities. Int J Syst Evolut Microbiol 57:81-91. doi:10. 1099/ijs.0.64483-0

Hall T (2011) BioEdit: an important software for molecular biology. GERF Bull Biosci 2:60-61

Hansen GH, Bergh O, Michaelsen J, Knappskog D (1992) Flexibacter ovolyticus sp. nov., a pathogen of eggs and larvae of Atlantic halibut, Hippoglossus hippoglossus L. Int J Syst Bacteriol 42:451-458

Huss VAR, Festl H, Schleifer KH (1983) Studies on the spectrophotometric determination of DNA hybridization from renaturation rates. Syst Appl Microbiol 4:184-192. doi:10. 1016/S0723-2020(83)80048-4

Kim O-S, Cho Y-J, Lee K, Yoon S-H, Kim M, Na H, Park S-C, Jeon YS, Lee J-H, Yi H, Won S, Chun J (2012) Introducing EzTaxon-e: a prokaryotic 16S rRNA gene sequence database with phylotypes that represent uncultured species. Int J Syst Evol Microbiol 62:716-721. doi:10.1099/ijs.0. 038075-0

Kim Y-O, Park S, Nam B-H, Jung Y-T, Kim D-G, Jee Y-J, Yoon J-H (2013) Tenacibaculum halocynthiae sp. nov., a member of the family Flavobacteriaceae isolated from sea squirt Halocynthia roretzi. Antonie Van Leeuwenhoek 103:1321-1327. doi:10.1007/s10482-013-9913-5

Kim M, Oh H-S, Park S-C, Chun J (2014) Towards a taxonomic coherence between average nucleotide identity and $16 \mathrm{~S}$ rRNA gene sequence similarity for species demarcation of prokaryotes. Int J Syst Evol Microbiol 64:1825. doi:10. 1099/ijs.0.064931-0

Ley JD, Cattoir H, Reynaerts A (1970) The Quantitative Measurement of DNA Hybridization from Renaturation Rates. Eur J Biochem 12:133-142. doi:10.1111/j.1432-1033. 1970.tb00830.x

López JR, Piñeiro-Vidal M, García-Lamas N, De La Herran R, Navas JI, Hachero-Cruzado I, Santos Y (2010) First isolation of Tenacibaculum soleae from diseased cultured wedge sole, Dicologoglossa cuneata (Moreau), and brill, Scophthalmus rhombus (L.). J Fish Dis 33:273-278. doi:10.1111/j.1365-2761.2009.01105.x

LPSN (2015) List of prokaryotic names with standing in nomenclature. http://www.bacterio.net/tenacibaculum. html

Nicholas KB, Nicholas HBJ, Deerfield DWI (1997) GeneDoc: analysis and visualization of genetic variation. EMBNEWNEWS 4:14

Olsen AB, Nilsen H, Sandlund N, Mikkelsen H, Rum H, Colquhoun DJ (2011) Tenacibaculum sp. associated with winter ulcers in sea-reared Atlantic salmon Salmo salar. Dis Aquat Org 94:189-199. doi:10.3354/dao02324

Piñeiro-Vidal M, Carballas CG, Gómez-Barreiro O, Riaza A, Santos Y (2008a) Tenacibaculum soleae sp. nov., isolated from diseased sole (Solea senegalensis Kaup). Int J Syst Evol Microbiol 58:881-885. doi:10.1099/ijs.0.65539-0

Piñeiro-Vidal M, Riaza A, Santos Y (2008b) Tenacibaculum discolor sp. nov. and Tenacibaculum gallaicum sp. nov., isolated from sole (Solea senegalensis) and turbot (Psetta maxima) culture systems. Int $\mathrm{J}$ Syst Evol Microbiol 58:21-25. doi:10.1099/ijs.0.65397-0

Piñeiro-Vidal M, Gijón D, Zarza C, Santos Y (2012) Tenacibaculum dicentrarchi sp. nov., a marine bacterium of the family Flavobacteriaceae isolated from European sea bass. Int J Syst Evol Microbiol 62:425-429. doi:10.1099/ ijs.0.025122-0

Rambaut A, Suchard MA, Xie D, Drummond AJ (2014) Tracer v1. 6. Available from http://beast.bio.ed.ac.uk/Tracer

Reiner K (2010) Catalse Test Protocol. American Society For Microbiology. http://www.microbelibrary.org/library/ laboratory-test/3226-catalase-test-protocol. 2014

Richter M, Rosselló-Móra R (2009) Shifting the genomic gold standard for the prokaryotic species definition. Proc Natl Acad Sci 106:19126-19131. doi:10.1073/pnas. 0906412106

Ronquist FT, van der Mark M, Ayres DL, Darling A, Höhna S, Larget B, Liu L, Suchard MA, Huelsenbeck JP (2012) MrBayes 3.2: efficient Bayesian phylogenetic inference and model choice across a large model space. Syst Biol 61:539-542. doi:10.1093/sysbio/sys029

Smibert MR, Krieg RN (1994) Phenotypic characterization. In: Gerhardt P, Murray RGE, Wood AW, Krieg RN (eds) Methods for general and molecular bacteriology. American Society for Microbiology, Washington D.C

Stackebrandt E, Goebel BM (1994) Taxonomic note: a place for DNA-DNA reassociation and $16 \mathrm{~S}$ rRNA sequence analysis in the present species definition in bacteriology. Int J Syst Bacteriol 44:846-849. doi:10.1099/00207713-44-4-846

Suzuki M, Nakagawa Y, Harayama S, Yamamoto S (2001) Phylogenetic analysis and taxonomic study of marine Cytophaga-like bacteria: proposal for Tenacibaculum gen. nov. with Tenacibaculum maritimum comb. nov. and Tenacibaculum ovolyticum comb. nov., and description of Tenacibaculum mesophilum sp. nov. and Tenacibaculum amylolyticum sp. nov. Int J Syst Evol Microbiol 51:1639-1652. doi:10.1099/00207713-51-5-1639

Tamura K, Stecher G, Peterson D, Filipski A, Kumar S (2013) MEGA6: Molecular Evolutionary Genetics Analysis version 6.0. Molecular Biology and Evolution doi:10.1093/ molbev/mst 197

Tanabe AS (2011) Kakusan4 and Aminosan: two programs for comparing nonpartitioned, proportional and separate models for combined molecular phylogenetic analyses of multilocus sequence data. Mol Ecol Resour 11:914-921. doi:10.1111/j.1755-0998.2011.03021.x

Tindall BJ, Rosselló-Móra R, Busse H-J, Ludwig W, Kämpfer P (2010) Notes on the characterization of prokaryote strains for taxonomic purposes. Int J Syst Evol Microbiol 60:249-266. doi:10.1099/ijs.0.016949-0

Toranzo AE, Magariños B, Romalde JL (2005) A review of the main bacterial fish diseases in mariculture systems. Aquaculture 246:37-61. doi:10.1016/j.aquaculture.2005.01.002

Vold V (2014) Challenge experiment with field isolates of Tenacibaculum spp. isolated from moribound Atlantic 
salmon (Salmo salar L). Master thesis. University of Bergen, 2014

Wakabayashi H, Hikida M, Masumura K (1986) Flexibacter maritimus sp. nov., a Pathogen of Marine fishes. Int J Syst Bacteriol 36:396-398. doi:10.1099/00207713-36-3-396

Wayne LG, Brenner DJ, Colwell RR, Grimont PAD, Kandler O, Krichevsky MI, Moore LH, Moore WEC, Murray RGE, Stackebrandt E, Starr MP, Trüper HG (1987)
Report of the ad hoc committee on reconciliation of approaches to bacterial systematics. Int J Syst Bacteriol 37:463-464

Ye J, Coulouris G, Zaretskaya I, Cutcutache I, Rozen S, Madden T (2012) Primer-BLAST: a tool to design target-specific primers for polymerase chain reaction. BMC Bioinformatics 13:134 